\title{
Antibodies to cultured rat heart cells in sera of patients with rheumatoid arthritis
}

\author{
R. MORE,$^{1}$ Z. STERN ${ }^{2}$ Y. GALON,${ }^{1}$ AND A. LAUFER ${ }^{1}$ \\ From the Departments of ${ }^{1}$ Pathology and ${ }^{2}$ Internal Medicine A, Hadassah Medical School, Jerusalem, Israel
}

SUMMARY Since heart lesions occur in many patients with rheumatoid arthritis (RA), sera from these patients were tested with an indirect fluorescent technique for antibodies reactive with rat heart cell cultures. Of 27 sera 22 had reactivity with non-muscle (nM) cells and 3 reacted with cultured beating muscle cells $(\mathrm{M})$. Positive sera reactive with $\mathrm{nM}$ cells exerted complementdependent cell cytotoxicity towards $\mathrm{M}$ cells. The $\mathrm{nM}$ antibodies were found to belong predominantly to the IgG class. They displayed no cross-reactivity with bovine collagen, human and bovine serum proteins, or human and sheep red blood cells. The relationship of these antibodies to the pathogenesis of RA heart lesions remains to be determined.

Rheumatoid arthritis (RA) is a systemic disorder of unknown aetiology involving especially the joints. It is characterised by persistent immunological abnormalities, including the formation of various autoantibodies. Antibodies to a variety of self-antigens including immunoglobulins, ${ }^{1}$ collagen, ${ }^{23}$ smooth muscle,${ }^{4}$ intermediate filaments, ${ }^{5}$ nuclear antigens, ${ }^{67}$ and fibroblasts ${ }^{8}$ have been identified in the sera and joint fluids of patients with RA. The pathogenic significance of most of these antibodies has yet to be determined.

A significant proportion of RA patients show clinical, echocardiographic, and histological signs of cardiac disease. ${ }^{9}$ It was therefore of interest to screen RA sera for the presence of antibodies reactive with cardiac antigens present on cultured neonatal rat heart cells, a popular and convenient substrate for various physiological, biochemical, pharmacological, and cardiological studies.

\section{Materials and methods}

Patients and sera. Twenty-three patients with no clinical evidence of ischaemic heart disease attending an outpatient rheumatology clinic with classical or definite RA, and 4 additional patients with probable RA, were studied. The patients' ages ranged from 25 to 67 years, the male to female ratio was $1: 4 \cdot 4$, and the mean disease duration was 11 years (range 2-24

Accepted for publication 27 September 1983.

Correspondence to Dr R. More, Department of Pathology, Hebrew University-Hadassah Medical School, POB 1172, Jerusalem, Israel. years). All patients were treated with non-steroidal anti-inflammatory drugs at the time of investigation. Additional treatment was: in 3 patients D-penicillamine, in 7 patients gold, and in 6 low doses of corticosteroids.

Healthy controls included 20 blood donors (A, B, $O$ blood groups) and laboratory staff members of both sexes (mean age 42 years).

Sera samples were collected, heat inactivated at $56^{\circ} \mathrm{C}$ for 30 minutes, and kept in aliquots at $-20^{\circ} \mathrm{C}$ until assay. Before being tested the sera were thawed and centrifuged in a Beckman microfuge for 5 minutes. Assessment of rheumatoid disease activity included clinical evaluation, erythrocyte sedimentation rate (ESR) by the Westergren method, and serum C-reactive protein estimations.

Cell cultures. Primary cultures of neonatal heart muscle (M) and non-muscle (nM) cells were established as described before.$^{10}$ Briefly, cells from 1-3 day old Sabra rats were disaggregated with $0 \cdot 1 \%$ trypsin and then suspended and washed in minimum essential medium (MEM) containing $10 \%$ fetal calf serum. After being filtered the cells were plated in 35 $\mathrm{mm}$ dishes containing glass coverslips for $1 \frac{1}{2}$ hours at $37^{\circ} \mathrm{C}$ in a humidified atmosphere of $95 \%$ air and $5 \%$ $\mathrm{CO}_{2}$. Non-adherent cells were then removed and the dishes were washed and replenished with $2.5 \mathrm{ml}$ MEM containing $10 \%$ fetal calf serum (FCS). The rapidly adherent cells were designated as 'nonmuscle' cells. The non-adherent cells were further depleted of non-muscle cells by incubation in a Falcon flask for 1 hour. The cultures enriched in muscle 
cells were then seeded into Petri dishes containing glass coverslips and grown as above. The $\mathrm{nM}$ and beating $M$ cell cultures were used for the immunofluorescent tests 3-4 days following seeding.

Immunofluorescent technique (IF). Anticardiac cell antibodies were detected by indirect immunofluorescence. Human sera were used neat or diluted 1:5-1:40 with phosphate buffered saline (PBS, pH $7 \cdot 4)$. Fluorescein conjugated sheep antihuman immunoglobulins (Hyland), rabbit antihuman immunoglobulins (Dako), swine antirabbit immunoglobulins, and rabbit antihuman $\kappa$ chains and rhodamin conjugated rabbit antihuman $\lambda$ chain (Dako) were used at a dilution of $1: 10$ with PBS. Incubations with unfixed or acetone fixed $\left(10 \mathrm{~min} 4^{\circ} \mathrm{C}\right)$ cultured muscle and non-muscle cells were carried out for 30 minutes at room temperature. A 3-step technique was employed for evaluation of IgG subclasses. Rabbit anti-IgG1, anti-IgG3, and anti-IgG4 were kindly donated by Dr D. Eilat and used at a dilution of 1:5 with PBS. The stained slides were examined by 2 independent observers with a Zeiss Universal fluorescence microscope. Specificity of the immune staining was checked by including known positive and negative sera with each test. The $M$ cell identity was confirmed with rabbit antihuman myosin (prepared in our laboratory).

Complement-dependent cytotoxic assay $(C D C) .{ }^{11}$ $M$ and $\mathrm{nM}$ cells prepared as described above were cultured in microtitre plates at a concentration of $10^{4}$ cells/well. The cells were incubated with human sera diluted 1:5 in the medium and 1:10 dilution of a selected non-cytotoxic fresh normal rabbit serum (complement source). Incubation was carried out for 48 hours at $37^{\circ} \mathrm{C}$. Following incubation the monolayers were washed with MEM medium containing $2 \%$ calf serum and labelled with $2 \mu \mathrm{Ci} \mathrm{Na}_{2}{ }^{51} \mathrm{CrO}_{4}$ for $45 \mathrm{~min}$. The wells were washed thoroughly with Hanks's medium containing $2 \%$ calf serum and replaced with $0.2 \mathrm{ml} 0.1 \mathrm{~N} \mathrm{NaOH}$. The solubilised well contents were counted in a gamma counter. Cytotoxicity was expressed as a percentage by the formula:

$$
1-\frac{\text { mean counts in } 5 \text { experimental wells }}{\text { mean counts in } 5 \text { normal control wells }} \times 100 \text {. }
$$

Absorption studies. Sera were absorbed with equal volumes of washed red blood cells (human, sheep, or bovine) or with washed glutaraldehyde polymerised $\operatorname{sera}^{12}$ (human or bovine) for 1 hour at room temperature and then again with an additional volume of absorbent for 18 hours at $4^{\circ} \mathrm{C}$. Absorption with 2 portions of $10 \mathrm{mg}$ insoluble bovine Achilles tendon collagen (Sigma type I) was carried out in the same way.

Rheumatoid factor activity was absorbed with glutaraldehyde polymerised pooled human gamma globlin $(40 \%$ saturated ammonium sulphate fraction) as described above.

\section{Results}

Anti-nM reactivity was detected in the sera of 22 out of 27 patients with RA and in only 2 out of 20 healthy controls, a highly significant finding $(p<0.001)$. Since the immunofluorescent staining was carried out routinely with living cells $(94-98 \%$ viability as determined by either trypan blue exclusion or fluorescein diacetate fluorochromasia) the recognised antigen was surface associated. The fluorescence pattern was usually patchy or beaded (Fig. 1). When the reaction was carried out with cold acetone fixed cells a similar fluorescent pattern was observed in most cases. Occasionally an additional filamentous cytoplasmic fluorescence and in 2 cases also nuclear fluorescence were observed. Reactivity with $\mathrm{nM}$ cells was usually detected up to a dilution of 1:20 and occasionally up to $1: 40$. Repeated testing of sera at intervals of several months yielded comparable results.

The $\mathrm{nM}$ cells did not bind heat-aggregated $\left(65^{\circ} \mathrm{C}\right.$ $10 \mathrm{~min}$ ) human, rabbit, goat, or guinea-pig gammaglobulins. Thus the described reactivity was not due to non-specific uptake of antiserum on to Fc receptors.

Nine out of the RA sera which were positive by

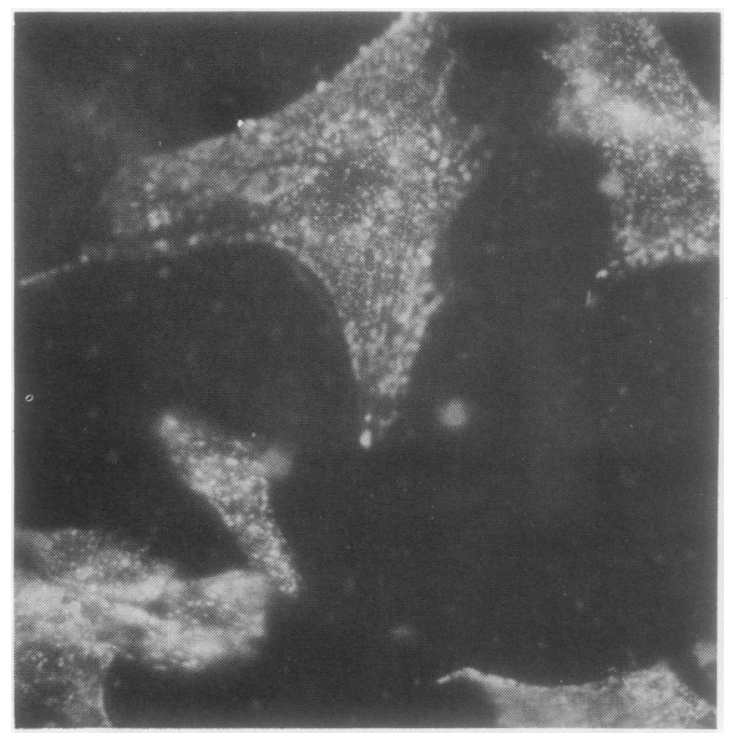

Fig. 1 Rat non-muscle ( $n M$ ) cells showing pattern of staining given by a rheumatoid serum. Indirect immunofluorescence; patient's serum 1:10, antihuman IgG FITC conjugate 1:10 $(\times 500$, pictured enlarged $\times 2 \cdot 4)$. 
indirect fluorescence were checked also for complement-dependent cellular cytotoxicity to $\mathrm{nM}$ cells. All 9 sera were found to be cytotoxic to the $\mathrm{nM}$ monolayers $(33 \pm 4 \cdot 7 \%)$. Five normal sera were found to exert no cytotoxicity on the nM monolayers (range $0-5 \%$ ). No cytotoxicity was discerned when heat-inactivated complement was used. Three RA sera which were negative in the immunofluorescence technique were likewise negative in the CDC technique.

There was an increased prevalence of immunofluorescent positivity in the group of patients with active disease ( 21 out of 23 ) as compared with 1 out of 4 in the quiescent patients, while no significant difference was found between rheumatoid factor seropositive and seronegative patients. Three out of 27 RA sera reacted with cultured $M$ cells, while 7 additional sera were marginally reactive. Reactivity with $\mathrm{M}$ cells was independent of that with $\mathrm{nM}$ cells.

The class of antibodies reacting with the cultured nM cells was determined for pooled RA sera by indirect immunofluorescence. The main reactivity was found with anti-IgG, while some reactivity was also detected with anti-IgM and anti-IgA. No reactivity was found with anti-IgD or anti-IgE. The antibodies were found to be polyclonal as judged by their reac!ivity with anti- $\kappa$ and anti- $\lambda$, anti-IgG1, antiIgG3, and anti-IgG4.

The relationship of the immune staining to rheumatoid factor (RF) reactivity was studied by absorption with polymerised human or rabbit IgG. Anti-IgG reactivity was not perceptibly changed, while anti-IgM showed a significant reduction of staining. The decrease in the staining with IgM might be attributed to rheumatoid factor reactivity with bound IgG antibodies.

Some initial studies were carried out to define the specificity of the involved nM cell antigen(s). Exhaustive absorption of the RA sera with pooled human A, B, O red blood cells or sheep red blood cells failed to reduce the immune staining of $\mathrm{nM}$ cells. On the other hand absorption with bovine red blood cells abolished the immunoactivity of the sera to these cells. Absorption with polymerised bovine serum had no such effect. No cross-reactivity with collagen occurred as judged by lack of reduction in immunostaining after absorption of pooled RA sera with insoluble bovine collagen. A pool of 3 positive sera also failed to stain reticulin ${ }^{13}$ in frozen sections of rat kidney and liver in the indirect fluorescent test.

\section{Discussion}

The present study demonstrates the presence of reactive antibodies to rat $\mathrm{nM}$ cells in sera of a high percentage of our patients with RA. The exact identity of the cultured cardiac non-muscle cells is not clear. They seem to consist of cardiac interstitial mesenchymal cells such as fibroblasts, pericytes, and possibly macrophages. ${ }^{14}{ }^{15}$ We could show that they do not contain muscle markers such as desmin and myosin nor the endothelial marker coagulation factor VIII (paper in preparation). These $\mathrm{nM}$ cells lack Fc receptors and thus are suitable for immunohistochemical work without interference of non-specific Fc binding on to the cells. We encountered such interference in some preliminary experiments with neonatal rat spleen fibroblasts.

The presence of antibodies reactive with these cells in the majority of active rheumatoid arthritic patients regardless of treatment or seropositivity for rheumatoid factor is of considerable interest and could contribute to the cardiotoxicity. The antibodies were found mainly in the IgG class and were capable of complement fixation. The reason for the incomplete cytotoxic effect on the nM cells is not clear, since the $\mathrm{nM}$ cells were previously found to be sensitive to complement-mediated cytotoxicity by rabbit and rat antisera. Heterogeneity of the cells, cell cycle differences in antigen expression, and immunomodulation of the antigens could explain the partial cytotoxicity. In preliminary studies attachment of human C3 to only a minority of nM cells coated with RA sera was found. At least one of the antigens recognised by the positive rheumatoid arthritis sera is a surface antigen and thus different from antibodies reactive with fibroblasts, reported recently. ${ }^{8}$ It is also different from known heterophile antigens, antibodies to which were described in rheumatoid arthritis sera. ${ }^{16}$ The absorption experiments with bovine red blood cells indicate cross-reactivity with $\mathrm{nM}$ cells. A similar cross-reactivity was reported between heart connective tissue antigens and bovine red blood cells with sera from rheumatic fever patients. ${ }^{17}$

Antibodies reactive with native and denatured collagen are present in a proportion of rheumatoid arthritis. ${ }^{23}$ The possibility that the antibodies described here recognise young collagen known to be secreted by various cultured cells was not excluded in the present study. However, the negative findings with collagen absorption and the use of early cultures grown in the absence of ascorbic acid seem to negate this possibility. Similar negative results were reported recently in studies of cultured synovial fibroblasts. ${ }^{18}$

Since several $\mathrm{nM}$ positive sera failed to react with rat kidney and liver, the antibodies seem to differ from the non-complement-fixing reticulin antibodies described in a small percentage of rheumatoid arthritis patients. ${ }^{13}$

The significance of the $\mathrm{nM}$ antibodies in relation to 
pathogenesis of cardiac lesions and their use in diagnosis remain to be determined. The antibodies described here might be the result of heart damage ${ }^{9}$ or alternatively may represent an additional manifestation of the immunological imbalance of the disease. Further correlative studies encompassing a larger series of patients are needed in order to clarify this point.

Finally, our findings might be of practical use in the recognition and immune elimination of non-muscle cells from mixed cardiac cell populations prepared for tissue culture, thus improving pure muscle cell growth without unwanted contaminants.

\section{References}

1 Stage D E, Mannik M. Rheumatoid factor in rheumatoid arthritis. Bull Rheum Dis 1973; 23: 720-6.

2 Steffen C, Timpl R. Antigenicity of collagen and its application in the serological investigation of rheumatoid arthritis sera. Int Arch Allergy Appl Immunol 1980; 22: 333-49.

3 Trentham D E, Kammer G M, McCune W J, David J R. Autoimmunity to collagen. A shared feature of psoriatic and rheumatoid arthritis. Arthritis Rheum 1981; 24: 1363-9.

4 Mellbye D J, Fyrand O, Brath H K, Olsen E. Oligoclonal immunoglobulins and smooth muscle antibodies in arthritic joints. Clin Exp Immunol 1980; 40: 103-10.

5 Osung $\mathrm{O} A$, Chandra M, Holborow E J. Antibody to intermediate filaments of the cytoskeleton in rheumatoid arthritis. Ann Rheum Dis 1982; 41: 69-73.

6 Hannestad K. Certain factors react with both IgG and an antigen associated with cell nuclei. Scand J Immunol 1978; 7: 127-36.
7 Zvaifler N J. Nuclear antigens and antinuclear antibodies: their role in joint inflammation. $J$ Rheumatol 1975; 2: 221-4.

8 Danilova T A, Mikhailova I N, Zhdanova L V, IvanovSmolensky R A, Lyampert I M. Study of antibodies to fibroblast antigens in the sera of rheumatic fever patients. Bull Exp Biol Med 1982; 94: 86-8.

9 Iveson J M I, Pomerance A. Cardiac involvement in rheumatoid arthritis. Clin Rheum Dis 1977; 3: 467-500.

10 Friedman I, Laufer A, Ron N, Davies A M. Experimental myocarditis. In vitro and in vivo studies of lymphocytes sensitized to heart extracts and group A streptococci. Immunology 1971; 20: 225-32.

11 More R, Yron I, Ben Sasson S, We iss D W. In vitro studies on cell mediated cytotoxicity by means of a terminal labeling technique. Cell Immunol 1975; 15: 382-91.

12 Avrameas S, Ternynk T. The cross-linking of proteins with glutaraldehyde and use for the preparation of immunoabsorbents. Immunochemistry 1969; 6: 53-66.

13 Williamson N, Asquith P, Stokes P L, Jowett A W, Cooke W T. Anti-connective tissue and other antitissue antibodies in the sera of patients with coeliac disease compared with the findings in a mixed hospital population. J Clin Pathol 1976; 29: 484-94.

14 Ahumada G G, Sobel B E, Needleman P. Cardiac prostaglandin synthesis. J Moll Cell Cardiol 1980; 12: 685-700.

$15 \mathrm{Nag} \mathrm{A} \mathrm{C.} \mathrm{Study} \mathrm{of} \mathrm{non-muscle} \mathrm{cells} \mathrm{of} \mathrm{the} \mathrm{adult} \mathrm{mammalian}$ heart: a fine structural analysis and distribution. Cytobios 1980; 28: 41-61.

16 Nishimaki T, Kano K, Milgrom F. Studies of heterophile antibodies in rheumatoid arthritis. Arthritis Rheum 1978; 21: 634-8.

17 Danilova T A, Lyampert I M. Immunofluorescence study of antibodies against connective tissue and muscle-fiber components of the myocardium in rheumatic fever patients. Bull Exp Biol Med 1972; 73: 300-2.

18 Gruhn W B, McDuffie F C. Studies of serum immunoglobulin binding to synovial fibroblast cell cultures from patients with rheumatoid arthritis. Arthritis Rheum 1980; 23: 10-6. 